\title{
Book Reviews/Comptes Rendus
}

Department of the Secretary of State of Canada. Federal and Provincial Support to Post-secondary Education in Canada: A Report to Parliament, 1985-86. Ottawa: Minister of Supply and Services Canada, 1985. Reviewed by Terry Wu, Faculty of Administration, The University of Regina.

This publication is the second annual report to Parliament on federal and provincial funding of postsecondary education in Canada. Basically, this report is a replica of the 1984-85 report with only minor modifications. Its primary purpose is to provide an up-to-date study on the financing of postsecondary education with the hope that it will assist politicians and policy makers in formulating policies pertinent to postsecondary education.

The report is organized into five sections. Part I provides a useful review of public support to postsecondary education in Canada since Confederation. Part II examines federal contributions to postsecondary education with emphasis on the Established Programs Financing and support of official language instruction. It also discusses the federal government's financial commitment to university research, student assistance, and the education of native people.

Part III deals with the diverse nature of higher education systems in the provinces. A portion of this section is devoted to provincial expenditure data on higher education as well as postsecondary enrolment by provinces.

Part IV outlines the rationale for federal funding of postsecondary education. Several standard arguments are briefly discussed, such as student accessibility and economic growth.

The final section examines the importance of continuing consultations between the federal and provincial governments regarding the funding of postsecondary education. It stresses the need for federal and provincial co-operation in several areas: student assistance, official languages, foreign students, human resources development and research.

The study's strength is in its broad overview of federal and provincial contributions to postsecondary education. It will be useful to anyone intent on acquiring familiarity with the financing of postsecondary education in Canada.

The report has many shortcomings, and several of these deserve mention. First, there is no overall framework of analysis in this study. Although the study covers a variety of topics, it fails to link different sections together. Each section is loosely organized and independent of the others. Since there are no structural linkages among sections, it is difficult to draw overall conclusions and make meaningful comparisons. Throughout the study, statistical data on federal and provincial contributions are provided, but no effort has been made to analyze these data. 
Some of the key issues on funding would be better understood if a more thorough analysis of the data were undertaken.

Second, treatment of some important issues is somewhat superficial or even ignored. For example, the discussion on the rationale for federal funding of postsecondary education is inadequate, and needs to be developed further. More importantly, the fiscal impact of the Established Programs Financing on provincial postsecondary education expenditures is not explored despite the availability of data for such an analysis.

Finally, the study lacks a concluding or summary section. One does not learn a great deal about the financial plight of Canadian universities by reading the last two sections of this report. A reader would have been better served with a brief summary of the major conclusions with particular emphasis on policy implications. It is just too fallacious to end abruptly with a discussion of the co-operation between the federal and provincial governments on matters relating to postsecondary education.

Despite its drawbacks, this report serves as a useful reference in providing higher education data for politicians and researchers. It is a serious attempt to provide relevant information on the financing of postsecondary education and relating this to the future existence of our universities and colleges so vital to the well-being of our country.

Governments and Higher Education: The Legitimacy of Intervention. Edited by Cecily Watson. Toronto: Ontario Institute for Studies in Education, 1987. Reviewed by Benjamin Levin, Executive Director, University Grants Commission of Manitoba.

This book is a compilation of papers originally presented at a conference, held at OISE in 1984, on the theme of the legitimacy of government intervention in higher education. A second volume is to apppear containing further papers from the conference.

Before commenting on the volume, it is appropriate to give a brief overview of the contents. There are three sections, following a keynote address by Harry Arthurs of York University. The first section contains seven papers on Canadian higher education and government. The second section includes papers on Britain, Australia, China, and a combined report dealing with Guyana and Tanzania. The third section has six papers dealing with the theme in relation to the United States.

As might well be expected in a book of papers from a conference, even one with a relatively circumscribed theme, the papers cover a wide variety of subjects from a wide variety of perspectives. Section one includes an historical overview by 